\title{
Chitosan-Graft-Poly(N-Tert-Butylacrylamide) Copolymer: Synthesis, Characterization and Optimization of Tetracycline Removal Using RSM
}

Mehtap Tanyol ( $\square$ mtanyol@munzur.edu.tr)

Munzur University https://orcid.org/0000-0002-3848-2581

Gülben Torğut

Munzur University: Munzur Universitesi

\section{Research Article}

Keywords: Graft copolymerization, chitosan, tetracycline, uptake, response surface methodology

Posted Date: April 8th, 2021

DOl: https://doi.org/10.21203/rs.3.rs-374211/v1

License: (c) (1) This work is licensed under a Creative Commons Attribution 4.0 International License.

Read Full License

Version of Record: A version of this preprint was published at Journal of Polymers and the Environment on July 15th, 2021. See the published version at https://doi.org/10.1007/s10924-021-02236-w. 


\title{
Chitosan-graft-poly(N-tert-butylacrylamide) Copolymer: Synthesis, Characterization and Optimization of Tetracycline Removal Using RSM
}

\author{
Mehtap Tanyol ${ }^{*}$, Gülben Torğut ${ }^{b}$
}

\begin{abstract}
${ }^{a^{*}}$ Munzur Unıversity, Faculty of Economics and Administrative Sciences, Department of Political Science and Public Administration, Department of Urbanization and Environmental Issues, TR62100, Tunceli, Turkey

${ }^{b}$ Munzur University, Tunceli Vocation School, Department of Chemistry and Chemical Processes, TR62100, Tunceli, Turkey
\end{abstract}

\begin{abstract}
*Correspondence to: Mehtap Tanyol
Address: Munzur Unıversity, Faculty of Economics and Administrative Sciences, Department of Political Science and Public Administration, Department of Urbanization and Environmental Issues, TR62000, Tunceli, Turkey; Tel.: +90 428 2131794-2480; Fax: +90 428 2131624; e-mail: mtanyol@munzur.edu.tr; ORCID: https://orcid.org/0000-0002-3848-2581
\end{abstract}

\begin{abstract}
In present study, graft copolymer was synthesized by free radical method using N-tertiary butylacrylamide monomer on chitosan which is an environment friendly polymer. The chemical structure and the surface morphology of the newly synthesized graft copolymer were determined by Fourier transform infrared spectroscopy (FT-IR), scanning electron microscopy (SEM), and X-ray diffraction (XRD). Thermal behavior was analyzed by thermogravimetric analysis (TGA). To investigate the applicability of chitosan-graft-poly( $N$-tert-butylacrylamide) graft copolymer, it was used as an adsorbent for rapidly removal of tetracycline from aqueous solution. Response surface methodology (RSM) was employed for the optimization of the study conditions such as adsorbent dosage (0.01-0.04 g), reaction time (10-90 minutes), and initial tetracycline concentration (10-100 mg $\left.100 \mathrm{~mL}^{-1}\right)$. The effects of these conditions on tetracycline uptake capacity were examined by RSM and the results were statistically analyzed. The RSM results showed that maximum tetracycline uptake capacity $\left(104.81 \mathrm{mg} \mathrm{g}^{-1}\right)$ was achieved at the adsorbent dose of $0.03 \mathrm{mg} 100 \mathrm{~mL}^{-1}$, reaction time of 51.12 minutes, and initial tetracycline concentration of $97.99 \mathrm{mg} \mathrm{L}^{-1}$. ANOVA analysis based on central composite design combined with RSM showed good agreement between experimental values and quadratic model estimates,
\end{abstract}


thus resulting in $0.9118 R^{2}$ for tetracycline uptake. The findings demonstrated chitosan-graftpoly( $N$-tert-butylacrylamide) copolymer is an effective adsorbent for pharmaceutical wastewater treatment.

Keywords: Graft copolymerization, chitosan, tetracycline, uptake, response surface methodology 


\section{Introduction}

In the last few decades, biodegradable materials have commercial potential due to their use in a variety of biomedical and environmental fields. It is possible to examine biodegradable polymers in two parts as synthetic and natural polymers. There are polymers produced from petroleum resources (non-renewable resources) or raw materials derived from biological resources (renewable resources) [1-3]. There is currently increasing interest in renewable natural polymers. Among these, chitosan has a special place due to its high adsorption capacity, biodegradability, and biocompatibility. It is utilized in pharmacology and medicine [4-6]. In addition to their use in wastewater treatment [7], food packaging [8], cosmetics [9], and textiles [10], they also have applications in drug delivery systems and tissue engineering [11]. The high chemical reactivity and high complexing ability of the amine and hydroxyl groups in the structure of chitosan make it possible to synthesize derivatives containing different functional groups and modify the chitosan molecule, which greatly expands the application of the biopolymer. Chitosan can be modified by different methods such as graft copolymerization reactions with synthetic monomers and preparation of mixtures with synthetic and natural polymers. [12-14]. In the literature, graft copolymer of chitosan with many monomers such as acrylamide, polyacrylonitrile, acrylates or methacrylates has been prepared. However, with alone $N$-tert-butylacrylamide (NTBA) used in our study, there is no graft copolymer and it was not used in the adsorption of tetracycline using $\operatorname{RSM}[15,16]$.

Pharmaceutical antibiotics have been defined as the permanent contaminants group in the world as a class of emerging pollutants $[17,18]$. It was noticed that many drugs such as antibiotics, antidepressants, chemotherapy agents were discharged into the water systems during production and use. Among these drugs, antibiotics with proven adverse effects are widely used. Antibiotic residue in the environment causes the increase of resistant microbes, threatening the ecosystem function and therefore human health $[19,20]$. Tetracycline is the second widely used antibiotic 
in the world, due to its broad spectrum activities, being cheap, low toxicity, and appropriate oral absorption in humans and animals [21-23]. In many studies it has found that tetracycline is poorly adsorbed in the digestive system of a living organism, with the majority being excreted through feces and urine [24]. Tetracycline is often detected in drinking water and wastewater and remove it completely is difficult. Therefore, developing an efficient and sustainable method to removal tetracycline from water is a priority for scholars, to improve water quality and reduce harm to public health and low-cost wastewater treatment technolgies. For this purpose, several techniques have been used for the treatment of wastewater including ozonation, microbial degradation, photocatalytic degradation, membrane filtration, and adsorption [25, 26]. Among them, adsorption is the most useful and applicable technique due to its advantages such as ease of use, affordable cost and high efficiency [27]. Various adsorbent types such as activated carbon, polymers, metal-based adsorbents, bioadsorbents have been used to remove antibiotics from aqueous solution $[21,28]$. But, some of these adsorbents have some disadvantages such as poor adsorption capacity, long equilibrium time and no regeneration. Recently, natural polymers with different functional groups within their surface area are accepted as suitable adsorbents because of reducing environmental concerns [29]. Chitosan offer a remarkable adsorbent alternative due to their unique physico-chemical properties, hydrophilicity, stability to most chemicals, and excellent adsorption capacity. In addition, it requires low cost, in case it used for removal of water [30].

RSM is a statistical and mathematical optimization technique based on polynomial equation prepared on experimental data [31-33]. It is applied when a response is affected by several variables. The aim is to optimize the selected variables simultaneously to achieve the best performance. It helps researchers to develop new methods with the least number of experiments [34]. Analysis of variance (ANOVA) is a very effective method to analyze the importance of many variables [35]. In this way, the most important factors can be evaluated efficiently. 
In this present work, the graft copolymer of chitosan with NTBA were prepared and used to optimize the removal of antibiotic named tetracycline from aqueous solution. The structural properties of the first synthesized graft copolymer were analyzed by FT-IR, SEM, and XRD. The effects of various parameters, namely, dose of adsorbent, reaction time, and initial concentration of tetracycline on the uptake capacity of tetracycline were studied by using RSM. As far as we know, chitosan-graft-poly(N-tert-butylacrylamide) graft copolymer has not been used for tetracycline removal. In addition, RSM technique has been rarely encountered before in tetracycline removal.

\section{Experimental}

\section{Materials}

Chitosan (product of Russia) with 100,000- 300,000 molecular weight was used without further purification. NTBA (Sigma-Aldrich, Germany), tetracycline (Sigma-Aldrich, Germany), 2,2'azobisisobutyronitrile (AIBN) (Sigma-Aldrich, Germany), acetic acid (Sigma-Aldrich, Germany), acetone (Labkon, Turkey), ethanol (Labkon, Turkey), and dioxane (Sigma-Aldrich, Germany) were used without any purification. All the chemicals used were of analytical grade.

\section{Equipment}

The copolymer was characterized by FT-IR (Jasco, USA) in the range of wave numbers 4000 $400 \mathrm{~cm}^{-1}$ using ATR. The morphology of the graft copolymer was evaluated by SEM which was performed by Hitachi SU-3500 (Japan) with an accelerating voltage of $15 \mathrm{kV}$. The XRD patterns were recorded on a powder X-ray diffractometer (Rigacu miniflex-600, Japan) at voltage $40 \mathrm{kV}$, current $15 \mathrm{~mA}$. TGA were conducted through a differential thermal analyzer (Shimadzu TGA- 
50, Japan) by using nitrogen gas and heat from ambient temperature to $600{ }^{\circ} \mathrm{C}$ at $10{ }^{\circ} \mathrm{C} \min ^{-1}$ heating rate. In tetracycline sorption process an orbital shaker (Zhicheng ZHWY-200B, China) at $200 \mathrm{rpm}$ was used. Adsorption properties were examined by using UV-Vis spectrophotometer (Shimadzu-1800, Japan).

\section{Grafting of Poly(N-tert-butylacrylamide) onto Chitosan}

NTBA monomer was grafted onto chitosan by free radical polymerization by using AIBN as an initiator at $65{ }^{\circ} \mathrm{C}$ for 6 hour under constant stirring. Chitosan $(0.5 \mathrm{~g})$ was dissolved in $50 \mathrm{~mL}$ of $1 \% \mathrm{v} / \mathrm{v}$ acetic acid solution. NTBA $(1 \mathrm{~g})$ and AIBN $(0.015 \mathrm{~g})$ were dissolved in a small amount of dioxane $(5 \mathrm{~mL})$. Then it mixed with the aqueous acetic acid solution of chitosan. The mixture was passed through nitrogen to provide an inert environment. At the end of the reaction, the solution was precipitated in a 50:50 acetone/ethanol and filtered. The obtained copolymer was firstly washed with distilled water and then with ethanol to remove the homopolymer or unreacted monomer present in the mixture. The graft copolymer dried in the oven at $50{ }^{\circ} \mathrm{C}$ for 24 hours and was weighed. Grafting percentage was calculated following Eq. (1):

$\%$ Grafting $=\frac{W_{1}-W_{2}}{W_{2}} \times 100$

where $\mathrm{W}_{1}(\mathrm{~g})$ is the mass of dried graft copolymer, $\mathrm{W}_{2}(\mathrm{~g})$ is the weight for chitosan.

\section{Tetracycline Adsorption Experiments}

Tetracycline (CAS Number: $60-54-8, \geq 98 \%$ pure, Molecular formula: $\mathrm{C}_{22} \mathrm{H}_{24} \mathrm{~N}_{2} \mathrm{O}_{8}$, Molecular weight: $444.43 \mathrm{~g} \mathrm{~mol}^{-1}$ ) was obtained from Sigma-Aldrich Company. Since tetracycline solutions 
are unstable, the required amount of tetracycline for each experiment was prepared by dissolving in distilled water. 20 experiments designed by central composite design were carried out to investigate the effect of initial tetracycline concentration $\left(10-100 \mathrm{mg} \mathrm{L}^{-1}\right)$, adsorbent dose $(0.01$ -

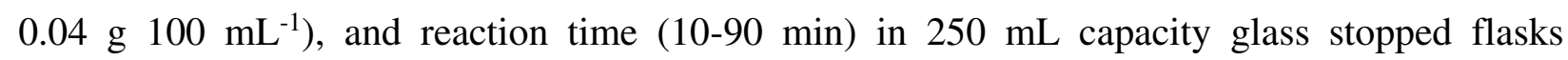
wrapped with aluminum foil including $100 \mathrm{~mL}$ of tetracycline, at $200 \mathrm{rpm}$ at room temperature $\left(25 \pm 2{ }^{\circ} \mathrm{C}\right)$, using a rotary shaker. Batch tetracycline adsorption experiments were performed at natural $\mathrm{pH}$ of solutions. After that, the samples were filtered through $0.45 \mu \mathrm{m}$ PVDF (polyvinylidene fluoride) filters, and the residual concentration of tetracycline was analyzed using a UV-Vis spectrophotometer at $\lambda=350 \mathrm{~nm}$ wavelength. The tetracycline uptake capacity $\left(q \mathrm{t}, \mathrm{mg} \mathrm{g}^{-1}\right)$ was calculated using Eq. (2) as follow [36]:

$q_{t}=\left(\frac{C_{o}-C_{t}}{m}\right) \times V$

where $C_{\mathrm{o}}$ and $C_{\mathrm{t}}$ are the initial and at $t$ time concentrations of tetracycline $\left(\mathrm{mg} \mathrm{L}^{-1}\right)$, respectively; $V$ is the volume of the solution (L), and $m$ : is the weight of adsorbent (g).

\section{Experimental Design for Tetracycline Adsorption and Statistical Analysis}

Experimental design allows simultaneous optimization of factors and leads to minimize error with the minimum number of runs and to improve performance characteristics [37]. In this study, the experiments for tetracycline removal were designed using RSM-based central composite design with three independent factors (initial tetracycline concentration $(A)$, adsorbent dose $(B)$, and reaction time $(C))$ at five levels $(-\alpha,-1,0,+1,+\alpha)$ using Design-Expert 7.0 with 20 runs. The experimental design points with the coded values of the factors utilized in the matrix of experiments consisted of eight factorial points, six axial points and six replicates at the center 
points are given in Table 1. The data from central composite design were analyzed by multiple regressions to fit the following second-degree polynomial equation according to Eq. (3) [38]:

$\mathrm{Y}=b_{0}+\sum_{i=1}^{k} b_{i} A_{i}+\sum_{i=1}^{k} b_{i i} A_{i}^{2}+\sum_{i=1}^{k-1} \sum_{j=i+1}^{k} b_{i j} A_{i} A_{j}+e$

where $Y$ represents tetracycline uptake capacity (predicted response); $b_{0}, b_{\mathrm{i}}, b_{\mathrm{ii}}$, and $b_{\mathrm{ij}}$ are the constant, linear, quadratic, and interaction coefficients, respectively. $A_{\mathrm{i}}$ and $A_{\mathrm{j}}(\mathrm{i}=1-3)$ are the coded variables affecting the response $Y$.

The values of the regression variables such as, $p$-value, the Fisher test value ( $F$-value), the regression coefficient $R^{2}$ and adjusted $R^{2}$ were calculated by using analysis of variance (ANOVA) and utilized for the determination of the suitability and relevance of the predicated model.

Table 1 Process factors and levels

\section{Results and Discussion}

\section{Characterization}

Free radical initiated graft copolymerization onto chitosan is carried out with NTBA monomer using AIBN initiator at $65{ }^{\circ} \mathrm{C}$. Grafting yield $(\% \mathrm{G})$ value were calculated using gravimetric data. $\% \mathrm{G}$ was experimentally reported as $80.8 \%$.

Fig. 1 The FT-IR spectrum of chitosan-graft-poly(N-tert-butylacrylamide) a) before tetracycline adsorption b) after tetracycline adsorption 
FT-IR spectra of chitosan-graft-poly( $N$-tert-butylacrylamide) is presented in Fig.1. The characteristic absorption bands belonging to N-tert-butylacrylamide were observed at about 3400 $\mathrm{cm}^{-1}$ secondary amide $(-\mathrm{NH})$, at $2867 \mathrm{~cm}^{-1} \mathrm{C}-\mathrm{H}$ stretching of $\mathrm{CH}_{2}$ and $\mathrm{CH}_{3}$ groups, at 1654 $\mathrm{cm}^{-1}$ stretching of amide carbonyl $(-\mathrm{HN}-\mathrm{C}=\mathrm{O}), 1564 \mathrm{~cm}^{-1}$ amide II $(-\mathrm{NH})$ and the band at 1222 $\mathrm{cm}^{-1}$ can be belong to the tertiary butyl groups $\left[-\mathrm{C}\left(\mathrm{CH}_{3}\right)_{3}\right][39,40]$. Also the characteristic bands of chitosan were observed in the spectrum. Many characteristic peaks of chitosan were seen in the FT-IR spectrum at $1655 \mathrm{~cm}^{-1}, 1638 \mathrm{~cm}^{-1}, 1561 \mathrm{~cm}^{-1}$, and $1320 \mathrm{~cm}^{-1}$ [41]. A peak at 1068 $\mathrm{cm}^{-1}$ is observed which is due to the $\mathrm{O}-\mathrm{H}$ bending vibration of a primary alcoholic group of chitosan [29, 42]. These observations showed that grafting of NTBA on chitosan has successfully occurred.

Fig. 2 The SEM image of chitosan-graft-poly(N-tert-butylacrylamide) a-b) before tetracycline adsorption c) after tetracycline adsorption

Surface morphology of chitosan-graft-poly( $N$-tert-butylacrylamide) graft copolymer before and after tetracycline adsorption was examined by SEM. The Fig. 2a and $2 b$ show that the copolymer has rough surfaces with randomly distributed porosity, which is a sign that poly( $N$-tert-butylacrylamide) has been successfully incorporated into chitosan. After tetracycline removal, in Fig. 2c, it is clear that the surface roughness of the copolymer was significantly reduced. This may suggest that removal of the antibiotic from water has occurred.

Fig. 3 XRD patterns of chitosan-graft-poly(N-tert-butylacrylamide) a) before tetracycline adsorption b) after tetracycline adsorption

To confirm the crystal structures of chitosan-graft-poly(N-tert-butylacrylamide) graft copolymer XRD was conducted and XRD patterns are shown in Fig. 3 before and after adsorption. In 
previous studies, pure chitosan is characterized by a scattering angle of $2 \theta=20^{\circ}$. This peak indicates that chitosan is an anhydrous crystal. Also typical fingerprints of semi-crystalline chitosan appear at $2 \theta=25^{\circ}[43,44]$. For our chitosan-graft-poly $(N$-tert-butylacrylamide $)$ graft copolymer, these peaks were observed at $19.9^{\circ}$ and $27.5^{\circ}$, respectively in Fig. 3a. This shows that the amorphous character increases with grafting. On the other hand, for the XRD spectra of chitosan-graft-poly( $N$-tert-butylacrylamide) graft copolymer after tetracycline removal (Fig. 3b) it can be observed a decrease in the intensity of the peak at $2 \theta=15^{\circ}$.

Fig. 4 TGA curves of chitosan-graft-poly(N-tert-butylacrylamide) a) before tetracycline adsorption $b$ ) after tetracycline adsorption

The heat stability and weight loss $(\%)$ of the chitosan-graft-poly( $N$-tert-butylacrylamide) were determined by TGA before and after tetracycline adsorption. As shown in Fig. 4a, thermal degradation was observed to occur in three stages. For before adsorption, degradation occurred at temperatures of $100{ }^{\circ} \mathrm{C}, 280{ }^{\circ} \mathrm{C}$, and $320{ }^{\circ} \mathrm{C}$ and weight losses of $15 \%$, 40\%, and $23 \%$, respectively. Compared to before adsorption, degradation took place in two steps for graft copolymer after tetracycline adsorption (Fig. 4b). A significant weight loss step of up to about $20 \%$ observed at $280{ }^{\circ} \mathrm{C}$ can be attributed to the loss of $\mathrm{H}_{2} \mathrm{O}$ molecules [45, 46]. The weight loss starting at about $320{ }^{\circ} \mathrm{C}$ may have occurred due to the degradation of poly $N$-tert-butylacrylamide groups [47]. Moreover, another steep weight loss of graft copolymer in $450-600{ }^{\circ} \mathrm{C}$ range implying the mass loss of the rest of chitosan. 


\section{Analysis of Variance (ANOVA) and Response Surface Plots for Tetracycline Adsorption}

The impact of operation factors on the tetracycline uptake capacity on chitosan-graftpoly( $N$-tert-butylacrylamide) was investigated and the experiments were made based on the central composite design. Table 2 shows the design matrix and response values.

For adsorption process, a quadratic model equation is obtained as shown in Eq. (4):

Tetracycline uptake capacity $\left(\mathrm{mg} \mathrm{g}^{-1}\right)=+39.96+21.50 A+9.59 B-8.48 C+13.44 A B-5.15 A C$

$$
+1.85 B C+3.29 A^{2}-8.71 B^{2}+4.79 C^{2}
$$

Table 2 Central composite design matrix and the response for tetracycline uptake capacity

Besides, the sufficient of the model equation in defining the experimental data was confirmed from the plot of predicted values from the model against the actual values (Fig. 5). Therefore, this plot clearly visualizes the performance of the model.

Fig. 5 Comparison plot between the actual and model predicted tetracycline uptake capacity

The regression coefficients and statistical significance of the model and the adequacy of the selected model were evaluated using analysis of variance (ANOVA) (Table 3). The larger the $F$ value of the model and the smaller the $p$-value means the more significant the applied model. The fact that the $F$-value and $p$-value of the model which is 11.49 is lower than 0.0500 shows that the model is significant at the $95 \%$ confidence level (Table 3). Similarly, $p$-values less than 0.0500 for $A$ (initial tetracycline concentration), $B$ (adsorbent dose), $C$ (reaction time), $A B$ (initial tetracycline concentration-adsorbent dose), and $B^{2}$ (adsorbent dose- adsorbent dose) indicate that these model terms are statistically significant for tetracycline adsorption with adsorbent. In this 
study, the coefficient of determination $\left(R^{2}\right)$ value calculated as 0.9118 shows that $91.18 \%$ of the changes in adsorption can be explained by the model. This has shown that the applied model can be reliable in predicting the uptake efficiency. The adjusted $R^{2}$ value was found to be 0.9123 . This is an important factor proving a good fit between experimental and predicted update efficiency for tetracycline adsorption of the model [48]. Adequation precision measures the signal-to-noise ratio and is desired to be greater than 4.0. As seen in Table 3, adequation precision value is 12.668 , which indicates that there is enough signal. The coefficient of variation $(\mathrm{CV})$ is a measure that expresses the standard deviation as a percentage of the mean. It explains the extent to which the data is distributed [49]. The acceptable values of CV $27.24 \%$ for tetracycline uptake capacity proved that the performed experiments were credible.

Table 3 Analysis of variance (ANOVA) for tetracycline uptake capacity

The tetracycline uptake capacity of the adsorbent over different combinations of independent factors was visualized by the 3D response surfaces curves (Fig. 6a-c). Since the adsorbent dosage provides the necessary surface area and binding sites for the adsorption of tetracycline, it is important to choose the appropriate amount of adsorbent. The plot of Fig. 6a illustrated the main and interaction effects of initial tetracycline concentration and adsorbent dose on the tetracycline uptake capacity, while fixing the reaction time at $50 \mathrm{~min}$. The tetracycline uptake

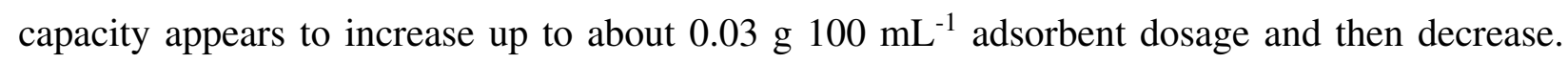
The increased adsorption is due to the more surface area available for contact. For the adsorbent

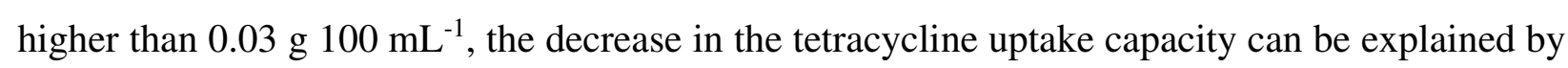
the decrease in the total surface area of the adsorbent due to particle-particle interaction, such as aggregation at higher dosages of the adsorbent [50]. The plot of Fig. 6b illustrated the main and interaction effects of initial tetracycline concentration and reaction time on the tetracycline uptake capacity, while fixing the adsorbent dose at $0.03 \mathrm{~g} 100 \mathrm{~mL}^{-1}$. With the increasing of initial 
tetracycline concentration, the tetracycline uptake capacity was increased. This is probably because the adsorbent is surrounded by more tetracycline ions due to the increased likelihood of contact between tetracycline molecules and adsorbent active sites. In other words, the higher the concentration of tetracycline, the more diffusion would consist from the polymer surface to the pores [51]. Similar behavior for the impact of tetracycline concentrations on the uptake capacity of tetracycline was observed and discussed for different adsorbents in the literature [52-54, 50]. The plot of Fig. 6c illustrated the main and interaction effects of adsorbent dose and reaction time on the tetracycline uptake capacity, while fixing the initial tetracycline concentration at 55 $\mathrm{mg} \mathrm{L}^{-1}$. The increase in the surface area required for adsorption together with the increasing adsorbent dosage led to a decrease in the adsorption time.

Fig. $63 \mathrm{D}$ dimensional response surface curve for (a) the effect of initial tetracycline concentration and adsorbent dose, (b) the effect initial tetracycline concentration and reaction time and (c) the effect of adsorbent dose and reaction time for the uptake of tetracycline onto chitosan-graft-poly(N-tert-butylacrylamide)

In this study, the experimental results were optimized by the numeric optimization program in the Design-Expert software. Optimum values of the factors studied for tetracycline removal and the maximum tetracycline uptake capacity are shown in Table 4. Utilizing the highest uptake capacity as the optimization target, the optimized conditions were founded as follows: initial tetracycline concentration of $97.99 \mathrm{mg} \mathrm{L}^{-1}$, adsorbent dose of $0.03 \mathrm{mg} 100 \mathrm{~mL}^{-1}$, and reaction time of $51.12 \mathrm{~min}$, and under this condition, the uptake capacity of $104.81 \mathrm{mg} \mathrm{g}^{-1}$ was obtained.

Table 4 Numerical value of the process factors for maximum tetracycline uptake capacity (Desirability=1.000) 


\section{Conclusions}

In this research, the effect of three factors, dose of chitosan-graft-poly( $N$-tert-butylacrylamide), reaction time, and initial tetracycline concentration on uptake capacity of tetracycline from wastewater have been studied. For this purpose, firstly the graft copolymer of $N$-tert-butylacrylamide and chitosan were prepared by free radical copolymerization method and characterized. The effects of adsorption parameters on the adsorption process were evaluated using the RSM approach. Modeling and optimization of tetracycline removal was examined by

using Stat-Ease Design Expert software version 7.0 by central composite design. ANOVA results showed that the applied model was statistically significant since the $p$-value was less than 0.0500. The design of the experiment revealed that the three parameters chosen were dependent and had significant effects on tetracycline uptake. High correlation found between experimental and predicted results $\left(R^{2}=0.9118\right)$

\section{Declarations}

Funding The study was financially supported by the Scientific Research Projects Department of Munzur University (Project No: PPMUB019-04).

Conflicts of interest/Competing interests The authors declare that there are no conflicts of interest.

Availability of data and material All relevant data are within the manuscript.

Code availability Not applicable. 
Ethical Approval Not applicable.

Consent to participate All authors were participated in this work.

Consent for publication All authors agree to publish.

\section{References}

1. Goryunova PE, Sologubov SS, Markin, AV, Smirnova NN, Mochalova AE, Zaitsev SD, Smirnova LA (2018) Calorimetric study of chitosan-graft-poly(2-ethylhexyl acrylate) copolymer. Thermochimica Acta 670:136-141

2. Thakur VK, Thakur MK, Kessler MR (2017) Handbook of composites from renewable materials. Scrivener Publishing LLC, Beverly

3. Dufresne A, Thomas S, Pothan LA (2013) Biopolymer nanocomposites: processing, properties, and applications. John Wiley \& Sons, Inc., Hoboken

4. Zakharova NV, Simonova MA, Zelinskii SN, Annenkov VV, Filippov, AP (2019) Synthesis, molecular characteristics, and stimulus-sensitivity of graft copolymer of chitosan and poly(N,N-diethylacrylamide). J Mol Liq 292:111355

5. Anitha A, Sowmya S, Sudheesh Kumara PT, Deepthi S, Chennazhi KP, Ehrlich H, Tsurkan M, Jayakumar R (2014) Chitin and chitosan in selected biomedical applications. Prog Polym Sci 39:1644-1667

6. Yang Z, Li P, McDonagh A, Li S, Lv M, Li Y, Yu Z, Feng C (2018) Chitosan-based nano-biocomposites and their applications in medicine and pharmaceutics. Curr Org Chem 22:628-640

7. Yang R, Li H, Huang M, Yang H, Li A, (2016) A review on chitosan-based flocculants and their applications in water treatment. Water Res 95:59-89

8. No HK, Meyers SP, Prinyawiwatkul W, Xu Z (2007) Applications of chitosan for improvement of quality and shelf life of foods: a review. J Food Sci 72(5):87-100

9. Aranaz I, Acosta N, Civera C, Elorza B, Mingo J, Castro C, de los Llanos Gandía M, Caballero AH (2018) Cosmetics and cosmeceutical applications of chitin, chitosan and their derivatives. Polymers 10(2):213

10. Lim SH, Hudson SM, (2003) Review of chitosan and its derivatives as antimicrobial agents and their uses as textile chemicals. J Macromol Sci Part C Polym Rev 43:223-269 
11. Riva R, Ragelle H, des Rieux A, Duhem N, Jérôme C, Préat V, (2011) Chitosan and chitosan derivatives in drug delivery and tissue engineering. Adv Polym Sci 244:19-44

12. Balan V, Verestiuc L, (2014) Strategies to improve chitosan hemocompatibility. Eur Polym J 53:171-188.

13. Zohuriaan-Mehr MJ, (2005) Advances in chitin and chitosan modification through graft copolymerization: a comprehensive review. Iran Polym J 14:235-265

14. Jenkins DWM, Hudson SM (2001) Review of vinyl graft copolymerization featuring recent advances toward controlled radicalbased reactions and illustrated with chitin/ chitosan trunk polymers. Chem Rev 101:3245-3273

15. Tripathy J, Mishra DK, Yadav M, Behari K (2010) Synthesis, characterization and applications of graft copolymer (chitosan-g-N, N-dimethylacrylamide). Carbohyd Polym 79:40-46

16. Pourjavadi A, Mahdavinia GR, Zohuriaan-Mehr MJ, Omidian H (2003) Modified chitosan. I. optimized cerium ammonium nitrate-induced synthesis of chitosan-gpolyacrylonitrile. J Appl Polym Sci 88:2048-2054

17. Rivera-Utrilla J, Sánchez-Polo M, Ferro-García MA, Prados-Joya G (2013) Pharmaceuticals as emerging contaminants and their removal from water. A review. Chemosphere 93(7):1268-1287

18. Liu Q, Zhong LB, Zhao QB, Frear C, Zheng YM (2015) Synthesis of $\mathrm{Fe}_{3} \mathrm{O}_{4}$ /polyacrylonitrile composite electrospun nanofiber mat for effective adsorption of tetracycline. ACS Appl Mater Interfaces 7:14573-14583

19. Zhao R, Ma T, Zhao S, Rong H, Tian Y, Zhu G (2020) Uniform and stable immobilization of metal-organic frameworks into chitosan matrix for enhanced tetracycline removal from water. Chem Eng J 382:122893

20. Chen X, Jiang X, Yin C, Zhang B, Zhang Q (2019) Facile fabrication of hierarchical porous ZIF-8 for enhanced adsorption of antibiotics. J Hazard Mater 367:194-204.

21. Ahamad T, Anis R, Chaudhary A, Naushad M, Alshehri SM (2019) Fabrication of $\mathrm{MnFe}_{2} \mathrm{O}_{4}$ nanoparticles embedded chitosan-diphenylureaformaldehyde resin for the removal of tetracycline from aqueous solution. Int J Bio Macromol 134:180-188

22. Zhang Y, Zuo S, Zhou M, Liang L, Ren G (2018) Removal of tetracycline by coupling of flow-through electro-Fenton and in-situ regenerative active carbon felt adsorption. Chem Eng J 335:685-692.

23. Cao J, Xiong Z, Lai B (2018) Effect of initial pH on the tetracycline removal by zerovalent iron: adsorption, oxidation and reduction. Chem Eng J 343:492-499. 
24. Ma J, Lei Y, Khan MA, Wang F, Chu Y, Lei W, Xia M, Zhu S (2019) Adsorption properties, kinetics \& thermodynamics of tetracycline on carboxymethyl-chitosan reformed montmorillonite. Int J Bio Macromol 124:557-567

25. Raeiatbin P, Sağ Açıkel Y (2017) Removal of tetracycline by magnetic chitosan nanoparticles from medical wastewaters. Desalination Water Treat 73:380-388.

26. Marzbali MH, Esmaieli M, Abolghasemi H, Marzbali MH (2016) Tetracycline adsorption by $\mathrm{H}_{3} \mathrm{PO}_{4}{ }^{-a c t i v a t e d ~ c a r b o n ~ p r o d u c e d ~ f r o m ~ a p r i c o t ~ n u t ~ s h e l l s: ~ A ~ b a t c h ~ s t u d y . ~}$ Process Saf Environ 102:700-709

27. Rizzi V, Lacalamita D, Gubitosa J, Fini P, Petrella A, Romita R, Agostianoa A, Gabaldón JA, Gorbe MIF, Gómez-Morte T, Cosma P (2019) Removal of tetracycline from polluted water by chitosan-olive pomace adsorbing films. Sci Total Environ 693:133620

28. Zhang X, Lin X, He Y, Chen Y, Luo X, Shang R (2019) Study on adsorption of tetracycline by $\mathrm{Cu}$-immobilized alginate adsorbent from water environment. Int $\mathrm{J}$ Biol Macromol 124:418-428.

29. Lalita, Singh AP, Sharma RK (2017) Selective sorption of Fe(II) ions over Cu(II) and $\mathrm{Cr}(\mathrm{VI})$ ions by cross-linked graft copolymers of chitosan with acrylic acid and binaryvinyl monomer mixtures. Int J Biol Macromol 105(1):1202-1212

30. Oladoja NA, Adelagun ROA, Ahmad AL, Unuabonah EI, Bello HA (2014) Preparation of magnetic, macro-reticulated cross-linked chitosan for tetracycline removal from aquatic systems. Colloids Surf B Biointerfaces 117:51-59

31. Ghasemi FA, Ghasemi I, Menbari S, Ayaz M, Ashori A (2016) Optimization of mechanical properties of polypropylene/talc/graphene composites using response surface methodology. Polym Test 53:283-292

32. Zare Y, Garmabi H, Sharif F (2011) Optimization of mechanical properties of $\mathrm{PP} /$ nanoclay $/ \mathrm{CaCO}_{3}$ ternary nanocomposite using response surface methodology. J Appl Polym Sci 122:3188-3200

33. Saad M, Tahir H, Khan J, Hameed U, Saud A (2017) Synthesis of polyaniline nanoparticles and their application for the removal of crystal violet dye by ultrasonicated adsorption process based on response surface methodology. Ultrason Sonochem 34:600608

34. Asfaram A, Ghaedi M, Hajati S, Goudarzi A, Bazrafshan AA (2015) Simultaneous ultrasound-assisted ternary adsorption of dyes onto copper-doped zinc sulfide nanoparticles loaded on activated carbon: optimization by response surface methodology. Spectrochim Acta A 145:203-212 
35. Fakhri A, Rashidi S, Tyagi I, Agarwal S, Gupta VK (2016) Photodegradation of erythromycin antibiotic by c- $\mathrm{Fe}_{2} \mathrm{O}_{3} / \mathrm{SiO}_{2}$ nanocomposite: response surface methodology modeling and optimization. J Mol Liq 214:378-383.

36. Mohammed AA (2015) Biosorption of lead, cadmium, and zinc onto sunflower shell: equilibrium, kinetic, and thermodynamic studies. Iraqi J Chem Petrol Eng 16:91-105

37. Kousha M, Tavakoli S, Daneshvar E, Vazirzadeh A, Bhatnagar A (2015) Central composite design optimization of Acid Blue 25 dye biosorption using shrimp shell biomass. J Mol Liq 207:266-273.

38. Torrades F, García-Montaño J (2014) Using central composite experimental design to optimize the degradation of real dye wastewater by Fenton and photo-Fenton reactions. Dyes Pigm 100:184-189.

39. Okudan A, Ataoglu BE, Sengoz O, Arslan G (2019) Cu(II) sorption performance of novel chitosan/ter-(vinylpivalate-maleic-anhydride- $N$-tert-butylacrylamide) microcapsules. J Polym Environ 27:2454-2463

40. Öztürk V, Okay O (2002) Temperature sensitive poly(N-tbutylacrylamide-co-acrylamide) hydrogels: synthesis and swelling behaviour. Polymer 43:5017-5026.

41. Metzler M, Chyli’nska M, Kaczmarek H (2015) Preparation and characteristics of nano silver composite based on chitosan-graft-acrylic acid copolymer. J Polym Res 22:146.

42. Bahramzadeh E, Yilmaz E, Adali T (2019) Chitosan-graft-poly(N-hydroxy ethyl acrylamide) copolymers: Synthesis, characterization and preliminary blood compatibility in vitro. Int J Biol Macromol 123:1257-1266

43. Topal M, Arslan Topal EI (2020) Optimization of tetracycline removal with chitosan obtained from mussel shells using RSM. J Ind Eng Chem 84:315-321

44. Kumar D, Kumar P, Pandey J (2018) Binary grafted chitosan film: Synthesis, characterization, antibacterial activity and prospects for food packaging. Int $\mathrm{J}$ Biol Macromol 115:341-348

45. Li Z, Liu Y, Zou S, Lu C, Bai H, Mu H, Duan J (2020) Removal and adsorption mechanism of tetracycline and cefotaxime contaminants in water by $\mathrm{NiFe}_{2} \mathrm{O}_{4}-\mathrm{COF}-$ chitosan-terephthalaldehyde nanocomposites film. Chem Eng J 382:123008

46. Gao C, Lin G, Lei Z, Zheng Q, Lin J, Lin Z (2017) Facile synthesis of core-shell structured magnetic covalent organic framework composite nanospheres for selective enrichment of peptides with simultaneous exclusion of proteins. J Mater Chem B 5:74967503. 
47. Save, NS. Jassal M, Agrawal AK (2005) Stimuli sensitive copolymer poly(N-tertbutylacrylamide-ran-acrylamide): Synthesis and characterization. J Appl Polym Sci 95(3):672-680,

48. Mohammadi R, Mohammadifar MA, Mortazavian AM, Rouhi M, Ghasemi JB, Delshadian Z (2016) Extraction optimization of pepsin-soluble collagen from eggshell membrane by response surface methodology (RSM). Food Chem 190:186-193

49. Li X, Quyang J, Xu Y, Chen M, Song X, Yong Q, Yu S (2009) Optimization of culture conditions for production of yeast biomass using bamboo wastewater by response surface methodology. Bioresour Technol 100:3613-3617

50. Sayğılı H, Güzel F (2016) Effective removal of tetracycline from aqueous solution using activated carbon prepared from tomato (Lycopersicon esculentum Mill.) industrial processing waste. Ecotoxicol Environ Saf 131:22-29

51. Pavlovic MD, Buntic AV, Mihajlovski KR, Siler-Marinkovic SS, Antonovic DG, Radovanovic Z, Dimitrijeviç-Brankovic SI (2014) Rapid cationic dye adsorption on polyphenol-extracted coffee grounds-A response surface methodology approach. J Taiwan Inst Chem Eng 45:1691-1699.

52. Zhu H, Chen T, Liu J, Li D (2018) Adsorption of tetracycline antibiotics from an aqueous solution onto graphene oxide/calcium alginate composite fibers. RSC Adv 8:2616-2621.

53. Mohammed AA, Kareem SL (2019) Adsorption of tetracycline fom wastewater by using Pistachio shell coated with $\mathrm{ZnO}$ nanoparticles: Equilibrium, kinetic and isotherm studies. Alex Eng J 58:917-928.

54. Wang Y, Gong S, Li Y, Li Z, Fu J (2020) Adsorptive removal of tetracycline by sustainable ceramsite substrate from bentonite/red mud/pine sawdust. Sci Rep 10:2960. 


\section{Table captions}

Table 1 Process factors and levels

Table 2 Central composite design matrix and the response for tetracycline uptake capacity

Table 3 Analysis of variance (ANOVA) for tetracycline uptake capacity

Table 4 Numerical value of the process factors for maximum tetracycline uptake capacity $($ Desirability $=1.000)$ 


\section{Figure captions}

Fig. 1 The FT-IR spectrum of chitosan-graft-poly(N-tert-butylacrylamide) a) before tetracycline adsorption b) after tetracycline adsorption

Fig. 2 The SEM image of chitosan-graft-poly(N-tert-butylacrylamide) a-b) before tetracycline adsorption c) after tetracycline adsorption

Fig. 3 XRD patterns of chitosan-graft-poly(N-tert-butylacrylamide) a) before tetracycline adsorption $b$ ) after tetracycline adsorption

Fig. 4 TGA curves of chitosan-graft-poly(N-tert-butylacrylamide) a) before tetracycline adsorption b) after tetracycline adsorption

Fig. 5 Comparison plot between the actual and model predicted tetracycline uptake capacity Fig. $63 \mathrm{D}$ dimensional response surface curve for (a) the effect of initial tetracycline concentration and adsorbent dose, (b) the effect initial tetracycline concentration and reaction time and (c) the effect of adsorbent dose and reaction time for the uptake of tetracycline onto chitosan-graft-poly(N-tert-butylacrylamide) 
Figures

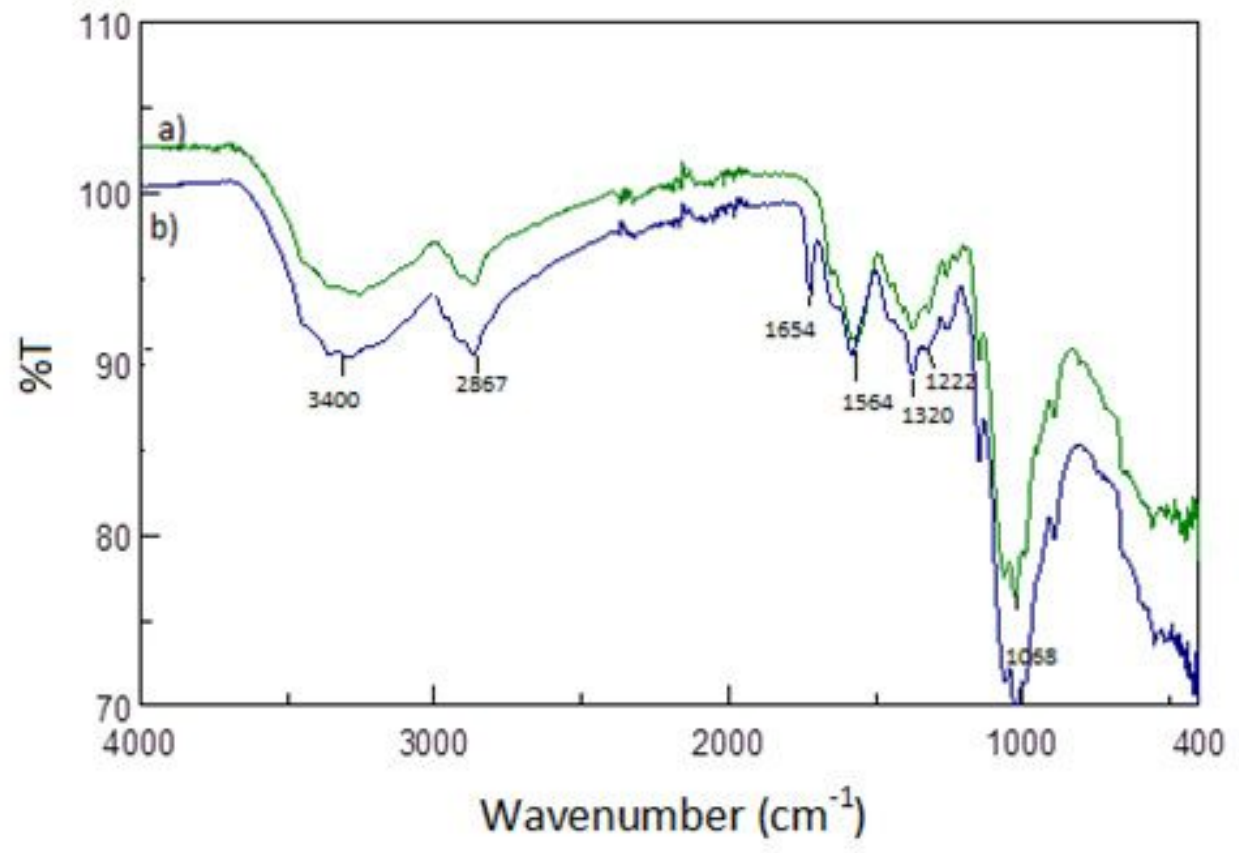

\section{Figure 1}

The FT-IR spectrum of chitosan-graft-poly(N囚tert囚butylacrylamide) a) before tetracycline adsorption b) after tetracycline adsorption 

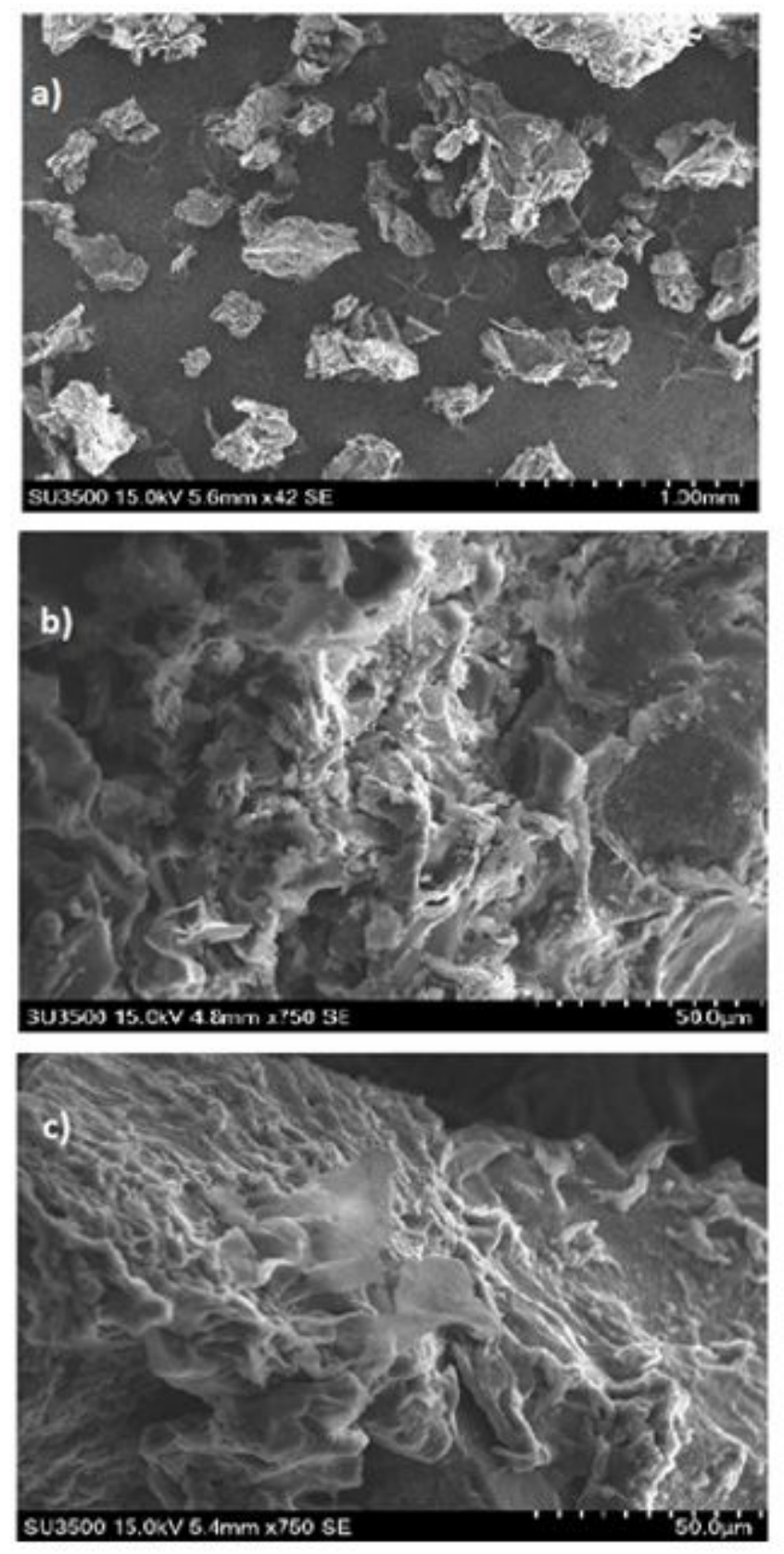

\section{Figure 2}

The SEM image of chitosan-graft-poly(N囚tert囚butylacrylamide) a-b) before tetracycline adsorption c) after tetracycline adsorption 

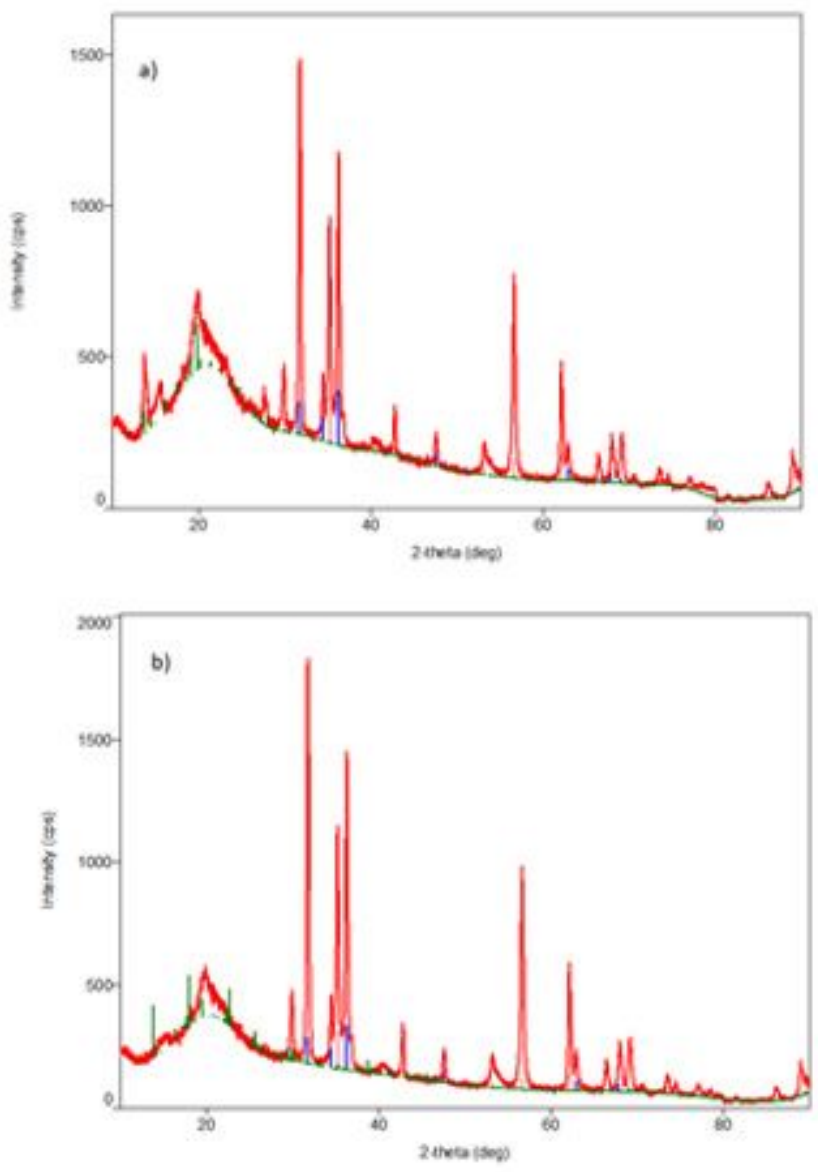

Figure 3

XRD patterns of chitosan-graft-poly(N囚tert 囚butylacrylamide) a) before tetracycline adsorption b) after tetracycline adsorption

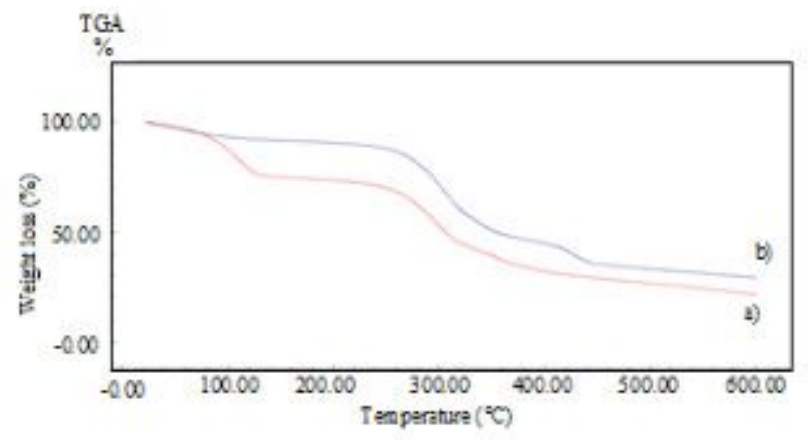

Figure 4

TGA curves of chitosan-graft-poly(N囚tert囚butylacrylamide) a) before tetracycline adsorption b) after tetracycline adsorption 


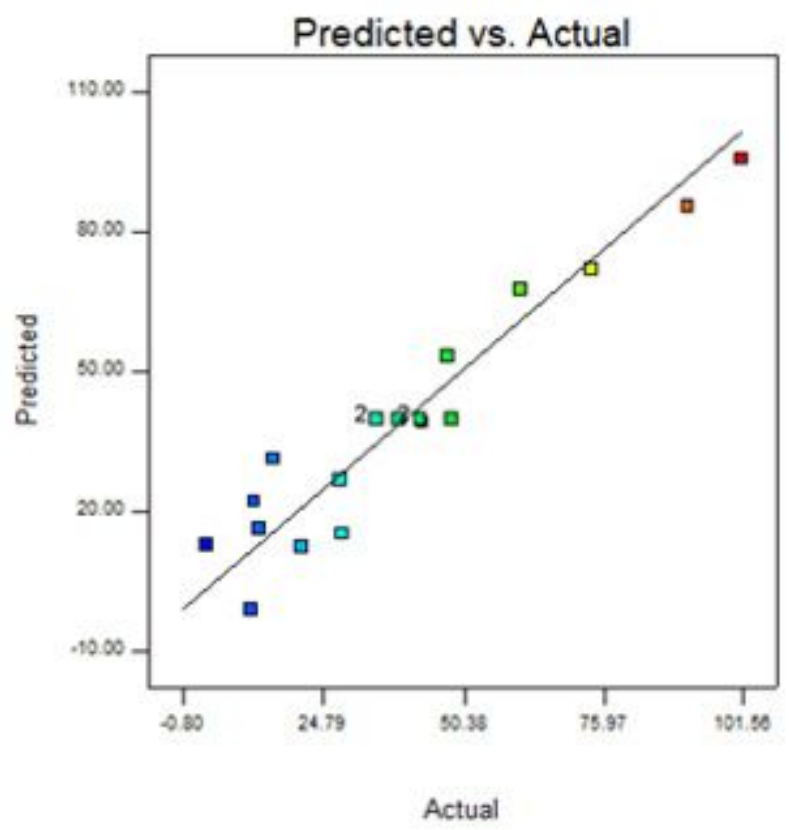

Figure 5

Comparison plot between the actual and model predicted tetracycline uptake capacity 

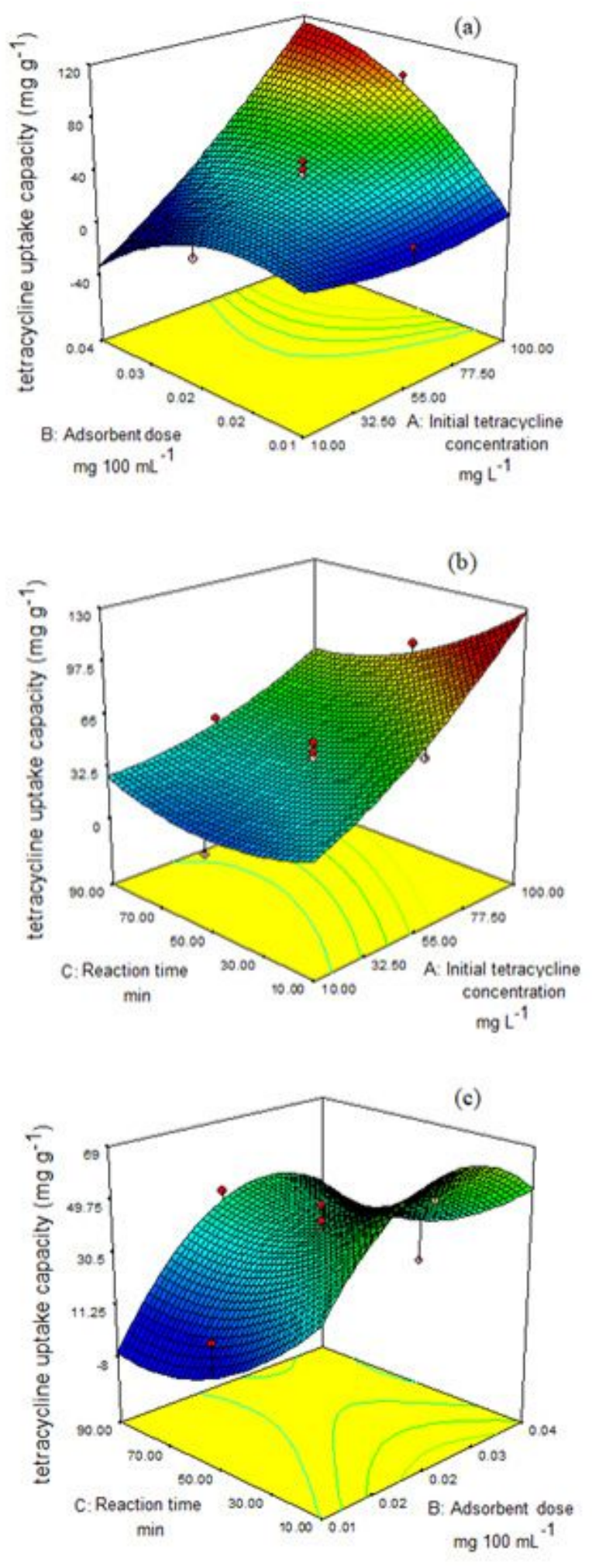

\section{Figure 6}

3D dimensional response surface curve for (a) the effect of initial tetracycline concentration and adsorbent dose, (b) the effect initial tetracycline concentration and reaction time and (c) the effect of adsorbent dose and reaction time for the uptake of tetracycline onto chitosan-graftpoly(N囚tert囚butylacrylamide) 